\title{
Delivery of written and verbal information on healthcare-associated infections to patients: opinions and attitudes of a sample of healthcare workers
}

\author{
Marco Bo*, Viola Amprino, Paola Dalmasso and Carla M. Zotti
}

\begin{abstract}
Background: Patients education is considered a valuable mean to prevent and control healthcare-associated infections (HAls). This cross-sectional study aims to assess declared practices of healthcare workers (HCWs) regarding the delivery of information about HAls to patients.

Methods: A 14-item multiple-choice questionnaire was designed to assess the attitudes and declared practices of HCWs (physicians, nurses and nursing assistants). Between October 2012 and October 2013, we surveyed a sample of HCWs from 4 acute hospitals in Piedmont (North-western Italy). Written information was available at three hospitals (A, B and C) and verbal information at the last one (hospital D).

Results: We surveyed 288 HCWs (79 physicians, 124 nurses and 85 healthcare assistants). At hospital A, B and C, 128 (71.6\%) HCWs declared that written information was usually delivered to any patient and 145 (66.5\%) that nurses usually delivered it. Only 42 (26.3\%) of them - 97.6\% nurses - declared that they usually delivered written information to patients. Among all surveyed HCWs, 210 (72.9\%) declared that patients also receive verbal information on HAl - mainly by nurses (70.8\%) and physicians (50\%) - but only $88(29,2 \%)-23.8 \%$ physician and 48.8\% nurses - declared that they usually informed patients. Finally, 83 (27.7\%) HCWs believed that they should decide whether or not to deliver information to patient case by case.

Conclusions: A formal policy requiring to deliver written information is most likely not enough to induce HCWs to better inform patients about HAls. Health Trusts might introduce more target actions to reinforce HCWs' practices, such as training and internal auditing.
\end{abstract}

Keywords: Access to Information, Hospitals, Cross-infections

\section{Background}

Healthcare-Associated Infections (HAIs) are the fourth leading cause of disease in the industrialized countries, where they are a major cause of morbidity and mortality among hospitalised patients [1]. Indeed, according to the last European point prevalence survey, on any given day, about 80,000 (5.7\%) patients in European acute care hospitals had at least one HAI [2]. At the same time, it is plausible that at least $20 \%$ of nosocomial infections are preventable [3]. Thus, the surveillance of HAIs and the

\footnotetext{
* Correspondence: m.bo@unito.it

Department of Public Health and Paediatrics Sciences, University of Turin, via Santena 5/bis, Turin 10126, Italy
}

development of appropriate policies for infection control have a high priority both in US and in EU [4].

Many studies have shown that multi-modal interventions can significantly reduce the rate of nosocomial infections, mainly bloodstream infections and urinary tract delivering general information on HAIs to every inpatient at admission through a recovery guidebook. 
Patients should also receive information tailored to the treatments delivered and to their individual risks of infection during their recovery, with special attention to patients who had acquired an HAI [5].

In 2009, the Council of Europe also recommended the delivery of general information on HAIs to every inpatient [6]. In the same period, in North-Western Italy, the Piedmont Regional Health Authority approved a policy recommending the delivery of written information on HAIs to every patient at admission to regional hospitals [7]. The availability of written material on HAIs for every inpatient was also included among the regional indicators for the prevention and control of HAIs.

Despite European and national recommendations, few data are available on the delivery of information on HAIs to patients. Only a French study showed that healthcare workers were not prone to inform their patients about the risk of contracting an HAI and no data are available on the Italian context [8]. Thus, we performed a cross-sectional survey to describe the attitudes and behaviours of healthcare workers on the delivery of information about HAIs.

\section{Methods}

We conducted a cross-sectional survey at 4 hospitals in Piedmont from October 2012 to October 2013. Information on HAIs was delivered through a recovery guidebook at one hospital (hospital A), through an informational leaflet at two hospitals (hospitals B and C), and no written information on HAIs was delivered at the last hospital (hospital D). Four to 6 wards were identified at every hospital and selected among internal medicine, specialised medicine (cardiology, oncology, haematology, respiratory disease and gastroenterology) and surgery units. We asked to complete the questionnaire to all healthcare workers (physicians, nurses and nursing assistants) who were attending to patients at any of the selected wards during the days of administration of the survey. We conducted the survey in different days of the week and at different hours of the day in each ward, to interview most of the healthcare workers employed at each of the units.

We designed a 14-item questionnaire to evaluate whether healthcare workers were aware of the policy in force at the hospital where they worked, on the ways such a policy was applied in the ward in which they operated and to examine their experiences and opinions about the information provided to patients about HAIs (see Additional file 1). Three of the questions were adapted from questions used in a previous survey [9]; the others were tailored to investigate whether HCWs applied the regional policy. Each question provided 1 to
4 closed answers, depending on the argument. Two resident doctors administered the questionnaires.

We validated the questionnaire through a survey of 30 patients, randomly selected at two of the hospitals. Then, Cohen's kappa was used to calculate the percentage of overall agreement on the questions investigating the HCWs' awareness on the policy in force (Q1-Q5, K $=0.77$; $\mathrm{Q} 1-\mathrm{Q} 10$ answer $1, \mathrm{~K}=0.8$ ). The way both to ask questions and to suggest their closed answers and to give explanations to the surveyed healthcare workers were discussed with the resident doctors during the pilot study.

The study was approved by the Ethics Committee of the University of Torino. Formal written authorisations to conduct the study were obtained by the administration of any participating hospital. An informational leaflet explaining the aim and the characteristics of the study was delivered to every participant. All participants gave their written consent to take part in the study.

\section{Statistical analysis}

Data were expressed as counts and percentages. Univariate analyses was performed using a chi-squared test or Fisher's exact test, as appropriate, to verify the existence of significant differences by qualification and by hospital.

All tests were two tailed, and the statistical significance level was set at 0.05 .

All of the analyses were performed using STATA SE 12.1.

\section{Results}

We surveyed 288 healthcare workers at four hospitals in the Piedmont: 79 physicians, 124 nurses and 85 nursing assistants. About $70 \%$ of respondents were females, mainly represented by nurses and nursing assistants $(85 \%)$. No significant differences were found by gender, age, qualification or ward among the hospitals. The characteristics of the sample are reported in Table 1.

In hospitals where any written informational materials on HAIs were available (A, B and C), 156 (72\%) HCWs were informed about the policy and almost all of them were able to describe the type of written material that ought to be delivered to the patients $(\mathrm{Q} 1$ and $\mathrm{Q} 2$, Table 2).

All the professionals working at hospitals B and C and the $94.6 \%$ of the ones working at hospital A reported that the informational material was available at their ward and $128(82.1 \%)$ of them stated that it was usually distributed to any inpatient able to read it at admission (Q3 and Q4, Table 2). On the contrary, according to 21 HCWs the information materials were not usually delivered to patients: $13(61.9 \%)$ declared that it would give a negative image to the hospital, while $8(38.1 \%)$ stated that they have not enough time to deliver it. 
Table 1 Characteristics of the sample

\begin{tabular}{|c|c|c|c|c|c|c|}
\hline & Hospital A $(n=56)$ & Hospital B $(n=73)$ & Hospital C $(n=89)$ & Hospital D $(n=70)$ & Total $(n=288)$ & $p$-value \\
\hline \multicolumn{7}{|l|}{ Gender } \\
\hline Female & $40(71.4)$ & $44(60.3)$ & $69(77.5)$ & $49(70.0)$ & $202(70.1)$ & 0.12 \\
\hline \multicolumn{7}{|l|}{ Age } \\
\hline 23-35 years & $17(30.4)$ & $13(17.8)$ & $26(29.2)$ & $23(32.8)$ & $79(27.4)$ & \multirow[t]{3}{*}{0.15} \\
\hline $36-55$ years & $35(62.5)$ & $49(67.1)$ & $58(65.2)$ & $38(54.3)$ & $180(62.5)$ & \\
\hline$>56$ years & $4(7.1)$ & $11(15.1)$ & $5(5.6)$ & $9(12.9)$ & $29(10.1)$ & \\
\hline \multicolumn{7}{|l|}{ Qualification } \\
\hline Physician & $10(17.9)$ & $27(37.0)$ & $27(30.4)$ & $15(21.4)$ & $79(27.4)$ & \multirow[t]{3}{*}{0.20} \\
\hline Nurse & $26(46.4)$ & $25(34.2)$ & $39(43.8)$ & $34(48.6)$ & $124(43.1)$ & \\
\hline Nursing assistant & $20(35.7)$ & $21(28.8)$ & $23(25.8)$ & $21(30.0)$ & $85(29.5)$ & \\
\hline \multicolumn{7}{|l|}{ Ward } \\
\hline Internal Medicine & $15(26.8)$ & 14 (19.2) & 29 (32.6) & $28(40.0)$ & $86(29.9)$ & \multirow[t]{3}{*}{0.07} \\
\hline Specialised Medicine & $14(25.0)$ & $29(39.7)$ & 29 (32.6) & $15(21.4)$ & $87(30.2)$ & \\
\hline Surgery & $27(48.2)$ & $30(41.1)$ & $31(34.8)$ & $27(38.6)$ & 115 (39.9) & \\
\hline
\end{tabular}

When asked who usually deliver information materials on HAI, most of the professionals (from $91.2 \%$ at hospital C to $100 \%$ at hospital B) declared that nurses usually deliver it to patients (Q5). When the answers were stratified by qualification (Table 3), we found that none of the physicians and only the $2.3 \%$ nursing assistants reported usually delivering such material. On the contrary, the $54 \%$ of the nurses stated that they usually or always distribute written information to their inpatients (Q11).

The way professionals delivered verbal information on HAIs also varied among the hospitals. Even if 210 (72.9\%) of all surveyed HCWs declared that patients usually receive verbal information on HAIs, this proportion was higher where written information material was available - ranging from $73.2 \%$ at hospital A to $87.7 \%$ at hospital B - than at hospital D (50\%), where only verbal information was administered (Q6, Table 2). Even in this case, almost all the professionals (from 94.3\% at hospital D to $100 \%$ at hospital A) declared that nurses usually delivered verbal information (Q7), but from 58.5\% (hospital A) to $75.0 \%$ (hospital B) of them also stated that physicians usually inform patients, without significant differences among the hospitals $(p=0.40$ and $p=0.35$ respectively). When the answers were stratified by qualification, the proportion of professionals who declared that they usually or always deliver verbal information were low among all the kind of professionals and varied among 25.3 to $33.1 \%$ (Q12, Table 3).

When we investigated single HCW's opinion regarding the need to inform each patients on the risk of acquiring an HAI, we found out that 91 (31.6\%) HCWs did not agree with the regional policy, especially among physicians. In particular, $36.7 \%$ of physicians, $26.6 \%$ of nurses and $24.7 \%$ of nursing assistants preferred to evaluate to give or not information case by case. Furthermore, 7.6\% of physicians preferred only to inform patients with an HAI or at higher risk of infection. The answers are similar when stratified among the hospitals (Q10, Tables 2 and 3).

Also, HCWs disagreed regarding the choice to give information to the patients' relatives $(\mathrm{Q} 8$, Table 2): while at hospital A, about a quarter of the HCWs declared that no information was given to the patients' relatives, such a proportion was limited at the other hospitals $(p<$ 0.001 ). Moreover, about a quarter of the respondents declared that information was only delivered to the patients' relatives when the patients were unable to read or understand information at hospital A and D or when they had acquired an HAI at hospital B and D.

Finally, 270 (93.8\%) of professionals who participated to the survey stated that patients do not usually ask questions regarding HAIs, without significant differences among qualifications $(p=0.32)(\mathrm{Q}$, Tables 2 and 3).

\section{Discussion}

This survey shows that a relevant percentage of the HCWs did not implement the regional policy requiring them to deliver written information on HAIs to all inpatients, even at hospitals where such a policy was formally adopted.

Our findings are partially comparable to ones presented in previous studies. Similar to Merle and colleagues [8], even in the present study, only a limited number of professionals reported to have personally given information on HAIs to patients, even though most of them stated that information was usually delivered to all inpatients at their ward. Also the proportions of HCWs who declared that they usually gave written or 
Table 2 Answers given by healthcare workers stratified by hospital

\begin{tabular}{|c|c|c|c|c|c|c|}
\hline Questions & Question asked to the healthcare workers & $\begin{array}{l}\text { Hospital A } \\
(n=56)\end{array}$ & $\begin{array}{l}\text { Hospital B } \\
(n=73)\end{array}$ & $\begin{array}{l}\text { Hospital C } \\
(n=89)\end{array}$ & $\begin{array}{l}\text { Hospital D } \\
(n=70)\end{array}$ & $p$ \\
\hline \multirow[t]{4}{*}{ Q1 } & $\begin{array}{l}\text { Do you know whether any WRITTEN } \\
\text { information on Healthcare-Associated } \\
\text { Infections is distributed to all } \\
\text { inpatients at admission? }\end{array}$ & & & & & \\
\hline & - Yes & $37(66.1)$ & $51(69.9)$ & $68(76.4)$ & $0(-)$ & $<0.001$ \\
\hline & - No & $19(33.9)$ & $22(30.1)$ & $21(23.6)$ & $70(100)$ & \\
\hline & If yes: & & & & & \\
\hline \multirow[t]{3}{*}{ Q2 } & $\begin{array}{l}\text { - What kind of informational material } \\
\text { is distributed in this hospital? }\end{array}$ & & & & & \\
\hline & - an informational leaflet & $0(-)$ & $50(98.0)$ & $68(100.0)$ & - & $<0.001$ \\
\hline & - an admission guidebook & $37(100.0)$ & $1(2.0)$ & $0(-)$ & - & \\
\hline \multirow[t]{3}{*}{ Q3 } & $\begin{array}{l}\text { - Is written informational material on } \\
\text { Healthcare-Associated Infection available } \\
\text { in the ward in which you work? }\end{array}$ & & & & & \\
\hline & - Yes & $35(94.6)$ & $51(100.0)$ & $68(100.0)$ & - & 0.06 \\
\hline & - No & $2(5.4)$ & $0(-)$ & $0(-)$ & - & \\
\hline \multirow[t]{4}{*}{ Q4 } & $\begin{array}{l}\text { - Is written informational material } \\
\text { distributed to any inpatient able } \\
\text { to read it at admission? }\end{array}$ & & & & & \\
\hline & - Yes & $28(75.7)$ & $32(62.7)$ & $68(100.0)$ & - & $<0.001$ \\
\hline & - No & $8(21.6)$ & $18(35.3)$ & $0(-)$ & - & \\
\hline & - I don't remember & $1(2.7)$ & $1(2.0)$ & $0(-)$ & - & \\
\hline \multirow[t]{4}{*}{ Q5 } & $\begin{array}{l}\text { - Who usually delivers informational } \\
\text { material on Healthcare-Associated } \\
\text { Infections to inpatients? }\end{array}$ & & & & & \\
\hline & -physicians & $0(-)$ & $0(-)$ & $0(-)$ & - & - \\
\hline & -nurses & $35(97.2)$ & $48(100.0)$ & $62(91.2)$ & - & 0.06 \\
\hline & - nursing assistants & $8(22.2)$ & $3(6.3)$ & $8(11.8)$ & - & 0.10 \\
\hline \multirow[t]{3}{*}{ Q6 } & $\begin{array}{l}\text { Do you know whether inpatients } \\
\text { receive any VERBAL information } \\
\text { on Healthcare-Associated Infections in } \\
\text { the ward in which you work? }\end{array}$ & & & & & \\
\hline & - Yes & $41(73.2)$ & $64(87.7)$ & $70(78.7)$ & $35(50.0)$ & $<0.001$ \\
\hline & - No & $15(26.8)$ & $9(12.3)$ & $19(21.3)$ & $35(50.0)$ & \\
\hline \multirow[t]{4}{*}{ Q7 } & $\begin{array}{l}\text { If yes, who usually gives verbal i } \\
\text { nformation on HAls to inpatients? }\end{array}$ & & & & & \\
\hline & - physicians & $24(58.5)$ & $48(75.0)$ & $48(70.6)$ & $24(68.6)$ & 0.35 \\
\hline & - nurses & $41(100.0)$ & $63(98.4)$ & $67(95.7)$ & $33(94.3)$ & 0.40 \\
\hline & - nursing assistants & $7(17.1)$ & $10(15.6)$ & $39(56.5)$ & $24(68.6)$ & $<0.001$ \\
\hline \multirow[t]{5}{*}{ Q8 } & $\begin{array}{l}\text { Do you know whether the patients' } \\
\text { relatives also receive any verbal } \\
\text { information on Healthcare-Associated } \\
\text { Infection in the ward in which you work? }\end{array}$ & & & & & \\
\hline & - Yes & $23(41.1)$ & $41(60.3)$ & $55(78.6)$ & $16(44.4)$ & $<0.001$ \\
\hline & - No & $14(25.0)$ & $3(4.4)$ & $6(8.6)$ & $1(2.8)$ & \\
\hline & $\begin{array}{l}\text { - only when the patient cannot read } \\
\text { or understand information }\end{array}$ & $13(23.2)$ & $5(7.4)$ & $6(8.6)$ & $10(27.8)$ & \\
\hline & - only when the patients has acquired an infection & $6(10.7)$ & $19(27.9)$ & $3(4.2)$ & $9(25.0)$ & \\
\hline Q9 & $\begin{array}{l}\text { Have you ever been asked for information on } \\
\text { Healthcare-Associated Infections by a patient? }\end{array}$ & & & & & \\
\hline
\end{tabular}


Table 2 Answers given by healthcare workers stratified by hospital (Continued)

\begin{tabular}{|c|c|c|c|c|c|c|}
\hline & - Never/sometimes & $55(98.2)$ & $70(95.9)$ & $78(87.6)$ & $67(95.7)$ & 0.06 \\
\hline & - Usually/always & $1(1.8)$ & $3(4.1)$ & $11(12.4)$ & $3(4.3)$ & \\
\hline \multirow[t]{5}{*}{ Q10 } & $\begin{array}{l}\text { In your opinion, which patients } \\
\text { should receive information on } \\
\text { the measures to prevent } \\
\text { Healthcare-Associated Infections? }\end{array}$ & & & & & \\
\hline & - Any inpatient & $41(73.2)$ & $43(58.9)$ & $64(71.9)$ & $49(70.0)$ & 0.51 \\
\hline & $\begin{array}{l}\text { - Only the inpatients at an } \\
\text { increased risk of acquiring a } \\
\text { healthcare-associated infection }\end{array}$ & $0(-)$ & $2(2.7)$ & $1(1.1)$ & $2(2.9)$ & \\
\hline & - Only the patients who are infected & $0(-)$ & $1(1.4)$ & $2(2.3)$ & $0(-)$ & \\
\hline & $\begin{array}{l}\text { - Healthcare professionals should } \\
\text { determine whether to give information } \\
\text { to the patients on a case-by-case basis }\end{array}$ & $15(26.8)$ & $27(37.0)$ & $22(24.7)$ & $19(27.1)$ & \\
\hline
\end{tabular}

verbal information to the patients is comparable to those reported by Duclos et colleagues among HCWs interviewed during 2004 at some short stay hospitals in Paris [10]. A further research carried out in Normandy in four hospitals with psychiatric activity has shown inadequate HCW's communications to the patients about HAIs [9].

At the same time, compared to Merle and colleagues [8], who reported that physicians were more likely than nurses to inform the patients, the present study shows the contrary. In particular, the distribution of written material on HAIs seems to be a task usually assigned only to nurses.

In our opinion, this fact may be mainly explained by organisational differences among the examined regions. Indeed, even if previous studies showed that nurses are usually more prone than physicians to follow recommendation [1], in Piedmont, the delivery of informational material on $\mathrm{HAI}$ is expected to be part of the tasks of the nurses who take care of the patients at their admission to the ward. Physicians most likely tell the patients about the risk of acquiring an HAI during clinical conversations preceding the acquisition of informed consent. This practice might explain why none of the physicians declared to deliver written information on HAI, while many of them stated to verbally inform patients, especially the ones working in a surgical unit.

More in general, our findings suggest that the simple launch of a policy requiring to deliver written informational material is most likely not enough to induce the HCWs to better inform their patients about the risk of acquiring an HAI.

As reported in previous studies, HCWs struggle to adopt behaviours recommended by policies and guidelines. Many factors may influence the possibility to really implement recommendations, such as workload and staff resources and the perceived inconvenience or usefulness to conform to single recommendations [1]. In our sample some of the HCWs complained about lack of time to inform patients and many of them seemed to disagreed with the regional policy. They preferred to decide whether or not to inform patients on a case by case basis or to inform only patients at higher risk of infection. Coherently, even Merle and coll. found that only approximately $17 \%$ of the interviewed professionals stated they usually gave verbal information to patients who had not acquired an HAI, while such a proportion increased to $31.6 \%$ of patients affected by an HAI [8]. Also, Leonard - who investigated the adherence to good practices among nurses caring for patients at the high risk of infection - found that approximately $95 \%$ of the oncology nurses reported that the personal risk of developing an infection and the ways to reduce it were usually discussed with the patients [11].

Also, as reported by Merle and coll., one of the main reasons why HCWs did not give information on HAI was the lack of frequent requests by the patients [8]. This result seems to be consistent with our findings because most of the professionals we interviewed, irrespective of their role, reported that the patients rarely ask for information on HAIs.

Finally, organization plays a relevant role. A strong support by the hospital management, the accessibility of local protocols and receiving specific training may improve adherence to care practices [1]. Also, HCWs seems to prefer direct ways of communication such as face to face or phone interactions - than indirect ones, such as policies. Thus, a persistent involvement of the hospital infection prevention and control team in verbal communication regarding ward problems in the management of infections may reinforce recommendations $[1,12]$.

This study has some limitations. We surveyed HCWs that belonged to hospitals with different 
Table 3 Answers given by healthcare workers stratified by qualification

\begin{tabular}{|c|c|c|c|c|c|}
\hline Question & Question asked to the healthcare workers & Physicians $(n=79)$ & Nurses $(n=124)$ & Nursing assistants $(n=85)$ & $p$ \\
\hline \multirow[t]{4}{*}{ Q1 } & \multicolumn{5}{|l|}{$\begin{array}{l}\text { Do you know whether any WRITTEN information } \\
\text { on Healthcare-Associated Infections is distributed } \\
\text { to all inpatients at admission? }\end{array}$} \\
\hline & - Yes & $36(45.6)$ & $76(61.3)$ & $44(51.8)$ & \multirow[t]{3}{*}{0.08} \\
\hline & $-\mathrm{No}$ & $43(54.4)$ & $48(38.7)$ & $41(48.2)$ & \\
\hline & If yes: & & & & \\
\hline \multirow[t]{4}{*}{ Q5 } & \multicolumn{5}{|l|}{$\begin{array}{l}\text { - Who usually delivers informational material } \\
\text { on Healthcare-Associated Infections to inpatients? }\end{array}$} \\
\hline & - physicians & $0(-)$ & $0(-)$ & $0(-)$ & - \\
\hline & - nurses & $34(97.1)$ & $70(93.3)$ & $41(97.6)$ & 0.60 \\
\hline & - nursing assistants & $0(-)$ & $9(12.0)$ & $10(23.8)$ & 0.004 \\
\hline \multirow[t]{3}{*}{ Q11 } & \multicolumn{5}{|l|}{ - Have you ever delivered it to your inpatients? } \\
\hline & - never/sometimes & $36(100.0)$ & $35(46.0)$ & $43(97.7)$ & \multirow[t]{2}{*}{$<0.00$} \\
\hline & - usually/always & $0(0.0)$ & $41(54.0)$ & $1(2.3)$ & \\
\hline \multirow[t]{4}{*}{ Q7 } & \multicolumn{5}{|l|}{$\begin{array}{l}\text { If inpatients receive any verbal information on } \\
\text { Healthcare-Associated Infections in the ward } \\
\text { you are working in, who usually gives it? }\end{array}$} \\
\hline & - physicians & $40(74.1)$ & $48(55.8)$ & $56(82.4)$ & 0.001 \\
\hline & - nurses & $52(96.3)$ & $84(97.7)$ & $68(97.1)$ & 0.88 \\
\hline & -nursing assistants & $12(22.6)$ & $32(37.2)$ & $36(51.4)$ & 0.005 \\
\hline \multirow[t]{3}{*}{ Q12 } & \multicolumn{5}{|l|}{$\begin{array}{l}\text { Have you ever given verbal information } \\
\text { on healthcare workers to your inpatients? }\end{array}$} \\
\hline & - never/sometimes & $59(74.7)$ & $83(66.9)$ & $62(72.9)$ & \multirow[t]{2}{*}{0.44} \\
\hline & - usually/always & $20(25.3)$ & $41(33.1)$ & $23(27.1)$ & \\
\hline \multirow[t]{3}{*}{ Q9 } & \multicolumn{5}{|l|}{$\begin{array}{l}\text { Have you ever been asked for information } \\
\text { on Healthcare-Associated Infections by a patient? }\end{array}$} \\
\hline & - never/sometimes & $76(96.2)$ & $113(91.1)$ & $81(95.3)$ & 0.32 \\
\hline & - usually/always & $3(3.8)$ & $11(8.9)$ & $4(4.7)$ & \\
\hline \multirow[t]{5}{*}{ Q10 } & \multicolumn{5}{|l|}{$\begin{array}{l}\text { In your opinion, which patients should receive } \\
\text { information on the measures to prevent } \\
\text { Healthcare-Associated Infections? }\end{array}$} \\
\hline & - Any inpatient & $44(55.7)$ & $90(72.6)$ & $63(74.1)$ & 0.01 \\
\hline & $\begin{array}{l}\text { - Only the inpatients at an increased risk } \\
\text { of acquiring a healthcare-associated infection }\end{array}$ & $4(5.1)$ & $1(0.8)$ & $0(-)$ & \\
\hline & - Only the patients who are infected & $2(2.5)$ & $0(-)$ & $1(1.2)$ & \\
\hline & $\begin{array}{l}\text { - Healthcare professionals should determine } \\
\text { whether to give the information to the } \\
\text { patient on a case by case basis }\end{array}$ & $29(36.7)$ & $33(26.6)$ & $21(24.7)$ & \\
\hline
\end{tabular}

Q5: multiple response question

${ }^{a}$ Questions asked only to HCWs who declared that any informational material was delivered to inpatients in the hospital where they were working (36 physicians, 76 nurses and 44nursing assistants)

policies and we did not evaluate if the IPC teams and the ward managers took specific actions to involved HCWs in patients education. Further the sample we extracted was not randomised and we did not collect data on HCWs' experience, such as years in practice and specific training on HAI prevention. Therefore, because the interview was trying to highlight working attitudes, corrected behaviours in line with the hospital policies may be overestimated.

\section{Conclusions}

Even if the availability of written informational material might support patients' education regarding HAIs, such policy might be reinforced by more focused strategies. For this purpose, it may be helpful to supply HCWs with special training on the matter, to offer auditing on the difficulties they confront in the improvement of this policy and to consider the proportion of patients receiving written information as an indicator of the quality of IPC strategies. 


\section{Additional file}

Additional file 1: Questionnaire used to conduct the survey. 14-item questionnaire designed to conduct the survey. (DOCX $17 \mathrm{~kb}$ )

\section{Abbreviations}

HAl: Healthcare-associated infection; HCW: Healthcare worker

\section{Acknowledgements}

We sincerely thank M. Campobasso, Infection Control Unit, Health Local Unit TO3; S. Barbaro, M. Gambino, C. Silvestre and S. Zozzoli, Molinette Hospita Infection Control Unit and P. Dal Maso, F. Meliga, Trauma Center Infection Control Unit, "Città della Salute e della Scienza di Torino" Hospital Trust; I. Vigna, Infection Control Unit, "Ordine Mauriziano" Hospital Trust; D. Griffa and G. Arditi, Infection Control Unit, Gradenigo Hospital for supporting this study in any of involved hospitals.

\section{Funding}

The authors declare that they received no funding to conduct this study.

\section{Availability of data and materials}

The datasets used and/or analysed during the current study are available from the corresponding author on reasonable request.

\section{Authors' contributions}

Conceptualization and design: All. Survey instrument development: MB, VA and CZ. Data collection: VA and MB. Data management and analyses: PD, VA and MB. Manuscript revisions: All. All authors read and approved the final manuscript.

\section{Competing interests}

The authors declare that they have no competing interests.

\section{Consent for publication}

Not applicable.

\section{Ethics approval and consent to participate}

The Ethics Committee of the University of Torino approved the study (approval date: $21^{\text {st }}$ March 2012). An informational leaflet explaining the aim and the characteristics of the study was delivered to every participant. All participants gave their written consent to take part in the study.

Received: 28 January 2016 Accepted: 16 January 2017

Published online: 23 January 2017

\section{References}

1. Zingg W, Holmes A, Dettenkofer M, Goetting T, Secci F, Clack L, et al. Hospital organisation, management, and structure for prevention of healthcare-associated infection: a systematic review and expert consensus. Lancet Infect Dis. 2015;15(2):212-24.

2. European Centre for Disease Prevention and Control. Point prevalence survey of healthcare-associated infections and antimicrobial use in European acute care hospitals. Stockholm: ECDC; 2013

3. Harbarth S, Sax H, Gastmeier P. The preventable proportion of nosocomial infections: an overview of published reports. J Hosp Infect. 2003;54(4):258-66.

4. Gastmeier P. Nosocomial infection surveillance and control policies. Curr Opin Infect Dis. 2004;17(4):295-301.

5. Ministère de la santé, de la famille, et des personnes handicapées. Circulaire DHOS\E2 - DGSISD5C N 21 du 22 janvier 2004 relative au signalement des infections nosocomiales et à l'information des patients dans les établissements de santé. Paris, 22 Janvier 2004.Available at: http://www. cclin-arlin.fr/Signalement/circulaire_21_220104.pdf. Accessed 20 Dec 2015.

6. Council of Europe. "Council Recommendation (2009/C 151/01): on patient's safety, including the prevention and control of healthcare associated infections." 2009. Available at: http://ec.europa.eu/health/patient_safety/ docs/council_2009_en.pdf. Accessed 20 Dec 2015.

7. Regione Piemonte. "Deliberazione della Giunta Regionale n 14-8500: Indicazioni alle Aziende sanitarie regionali per la gestione del rischio clinico e l'attivazione dell'Unita' di gestione del rischio clinico e prime linee di indirizzo su tematiche di particolare interesse." 2008. Available at: http:// www.regione.piemonte.it/governo/bollettino/abbonati/2008/16/siste/ 00000168.htm. Accessed 20 Dec 2015.

8. Merle V, Tavolacci MP, Moreau A, Dubreuil N, Dollois B, Gray C, et al. What factors influence healthcare professionals' opinion and attitude regarding information for patients about hospital infection? J Hosp Infect. 2007;66(3): 269-74.

9. Audureau E, Merle VK, Kerleau B, Dollois M, Baugé-Rousseau S, Théry MP, et al. Information for patients about hospital infections in psychiatry: an assessment of healthcare professionals' knowledge, opinion and attitude. Encéphale. 2010;36(2):132-8.

10. Duclos A, Gillaizeau F, Colombet I, Coste J, Durieu P. Health staff perception regarding quality of delivered information to inpatients. International J Qual Health Care. 2008;20(1):13-21.

11. Leonard K. A European survey relating to cancer therapy and neutropenic infections: nurse and patient viewpoints. Eur J Oncol Nurs. 2012;16(4):380-6.

12. Edwards R, Sevdalis N, Vincent C, Holmes A. Communication strategies in acute health care: evaluation within the context of infection prevention and control. J Hosp Infect. 2012:82(1):25-9.

\section{Submit your next manuscript to BioMed Central and we will help you at every step:}

- We accept pre-submission inquiries

- Our selector tool helps you to find the most relevant journal

- We provide round the clock customer support

- Convenient online submission

- Thorough peer review

- Inclusion in PubMed and all major indexing services

- Maximum visibility for your research

Submit your manuscript at www.biomedcentral.com/submit
Biomed Central 